\title{
Systematic review and meta-analysis of laparoscopic mesh versus suture repair of hiatus hernia: objective and subjective outcomes
}

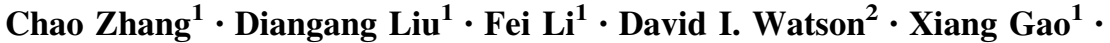 \\ Jan H. Koetje ${ }^{2}$ Tao Luo ${ }^{1}$ Chao Yan $^{1} \cdot$ Xing Du$^{1} \cdot$ Zhonggao Wang $^{1}$
}

Received: 4 February 2017/ Accepted: 2 May 2017/Published online: 18 May 2017

(c) The Author(s) 2017. This article is an open access publication

\begin{abstract}
Background Hiatus hernia (HH) contributes to the pathophysiology of gastroesophageal reflux disease (GERD). Mesh-augmentation of surgical repair might be associated with a reduced risk of recurrence and GERD. However, recurrence rates, mesh-associated complications and quality of life (QOL) after mesh versus suture repair are debated. The aim of this meta-analysis was to determine $\mathrm{HH}$ recurrence following mesh-augmentation versus suture repair. Secondary aims were to compare complications, mortality, QOL and GERD symptoms following different repair techniques.

Methods A systematic literature search of the PubMed, Medline, Embase, Cochrane Library, and Springer database was performed to identify relevant studies comparing mesh-augmentation versus suture repair of the esophageal hiatus. Data pertinent to the benefit versus risk outcomes for these techniques were extracted and compared by metaanalysis. The odd ratio (OR) and mean differences (MD) with $95 \%$ confidence intervals were calculated.
\end{abstract}

Chao Zhang and Diangang Liu have contributed equally to this work.

Fei Li

feili35@126.com

$\triangle$ David I. Watson

david.watson@flinders.edu.au

$\triangle$ Zhonggao Wang

wangzg35@126.com

1 Department of General Surgery, Xuanwu Hospital, Capital Medical University, No. 45 Changchun Street, Xicheng District, Beijing 100053, China

2 Flinders University Department of Surgery, Flinders Medical Centre, Bedford Park, SA 5042, Australia
Results Eleven studies (4 randomized, 9 non-randomized) comparing mesh $(n=719)$ versus suture $(n=755)$ repair were identified. Mesh-augmentation was associated with a reduced overall recurrence rate compared to suture repair [2.6 vs. 9.4\%, OR 0.23 (95\% CI 0.14-0.39), $P<0.00001]$. There was no significant difference in the incidence of complications $(P=0.400)$ between groups. Improvement in QOL measured by SF-36 was greater following biological mesh-augmentation compared to suture repair (MD $=13.68,95 \%$ CI $2.51-24.85, P=0.020)$, as well as GERD-HRQL. No differences were seen for the GIQLI scores with permanent mesh $(P=0.530)$. Dysphagia improvements were better following suture repair $(\mathrm{MD}=1.47,95 \%$ CI $0.20-2.74, P=0.020)$.

Conclusions Mesh repair of HH conferred some advantages and disadvantages at short-term follow-up. Compared to a suture repair alone, mesh-augmentation might be associated with less short-term recurrences, and biological mesh was associated with improved short-term QOL. However, these advantages were offset by more dysphagia. Long-term outcomes are still needed to determine the place of mesh repair of $\mathrm{HH}$.

Keywords Hiatus hernia - Hiatal repair - Mesh · Gastroesophageal reflux disease (GERD) - Quality of life (QOL)

$\begin{array}{ll}\text { Abbreviations } & \\ \text { CI } & \text { Confidence intervals } \\ \text { GERD } & \text { Gastroesophageal reflux disease } \\ \text { GERD-HRQL } & \text { GERD related Health Related Quality of } \\ & \text { Life } \\ \text { GQOLI } & \text { Gastrointestinal Quality of Life Index } \\ \text { HH } & \text { Hiatus hernia } \\ \text { MD } & \text { Mean differences }\end{array}$




$\begin{array}{ll}\text { OR } & \text { Odds ratio } \\ \text { RCT } & \text { Randomized controlled trial } \\ \text { QOL } & \text { Quality of Life } \\ \text { SF-36 } & \text { Short-form } 36\end{array}$

While laparoscopic fundoplication is a well-established option for the treatment of gastroesophageal reflux disease (GERD), controversy exists about the best technique for repair of hiatus hernia $(\mathrm{HH})$, and how to minimize the risk of hernia recurrence [1]. Mesh-augmented hiatal repair has been proposed as a solution which might reduce the risk of recurrence, and a range of different techniques, mesh shapes, and mesh types has been proposed [2,3]. The main indication for mesh-augmented hiatal repair is a large paraesophageal hernia. However, some surgeons also advocate the routine use of mesh repair for smaller sliding HHs [4]. On the other hand, the disadvantages of meshaugmentation include the risk of serious complications related to the use of prosthetic material, such as esophageal erosion and stenosis, mesh migration, local fibrosis, and dysphagia [5]. Even with the use of biological mesh, postoperative dysphagia is still reported in $12-17.5 \%$ of patients [6]. For these and other reasons, mesh-augmentation of $\mathrm{HH}$ repair remains controversial.

If mesh repair is to be routinely adopted into surgical practice, its use should minimize the risk of hernia recurrence without increasing the risk of complications and other adverse outcomes. It is also possible that subsets of patients might benefit from mesh repair whereas others might not. For example, the size of the hernia or hiatal defect might be an important factor in determining the need or otherwise for mesh [7, 8]. Previous literature reviews $[7,9]$ have summarized available data for hernia recurrence following primary suture repair versus mesh-augmentation using various mesh types, but without analyzing the impact of hernia size on outcome. In addition, while current evidence $[10,11]$ suggests mesh-augmentation is not associated with an increase in risk of perioperative complications, previous systematic reviews [11] have not considered the issue of postoperative dysphagia or other issues which can occur following both suture repair and mesh-augmentation. These previous meta-analyses $[9,11]$ have all focused on the scope of objective investigations and hernia recurrence rates, and subjective outcomes such as GERD symptoms and global outcome measures have not been considered.

In this paper, we report the outcomes for a systematic review of the literature and meta-analysis of outcomes following laparoscopic mesh-augmentation versus suture repair of HH. Clinical outcomes were compared following surgical repair, including recurrence rates, complications, and postrepair dysphagia. We also reviewed the impact of hernia size on outcome to determine whether recurrence is impacted by hernia size following hiatal repair with mesh-augmentation. Finally, the impact of different methods of repair on quality of life (QOL) outcomes was also determined.

\section{Materials and methods}

This meta-analysis was conducted and the results are presented according to the recommendations of PRISMA statement [12].

\section{Search strategy}

PubMed, Medline, Embase, Cochrane Library, and Springerlink electronic databases were searched until October 2016. A manual search of the reference listed from the articles accessed was also performed to identify other relevant studies. Only articles written in English were searched. A search strategy using disease-specific terms (e.g., gastroesophageal reflux OR hernia, hiatal OR hiatus hernia), management-specific terms (e.g., mesh OR implant OR patch), and terms related to surgical procedures (e.g., laparoscopic surgery OR laparoscopy OR minimally invasive) was used.

\section{Inclusion criteria and exclusion criteria}

Inclusion criteria were as follows: (i) randomized controlled trials (RCTs) or case-control comparative studies in patients who underwent repair of $\mathrm{HH}$ with the use of mesh (permanent or absorbable/biologic), (ii) age $\geq 16$ years, (iii) a laparoscopic approach was used in all patients, (iv) duration of follow-up $\geq 12$ months, (v) raw data could be extracted from studies to calculate outcomes, (vi) patients were diagnosed preoperatively with GERD or any type of HH. Exclusion criteria were as follows: (i) Studies were non-comparative, (ii) mesh was not used, (iii) the hernia was repaired without a fundoplication, (iv) patients aged $<16$ years were included, (v) studies for which raw data could not be extracted to obtain pooled results and the corresponding author was not able or willing to provide revelent additional data at request for this study.

\section{Data extraction}

Titles and abstracts of the citations were identified and scrutinized by two of the authors (C Zhang and D Liu) to determine eligibility for inclusion in the pooled analysis. Data were then extracted from the full publication. This comprised (i) descriptive information relevant to each study-first author, publication year, study population characteristics, study design, sample size, follow-up 
duration, and inclusion/exclusion criteria, and (ii) data required for outcomes analysis, including beneficial and adverse results. Any disagreements between the two reviewers were resolved by discussion and consensus. If data were missing, the authors of the original studies were contacted and the relevant information was requested. Outcomes of interest in studies in which the same cohort was published in more than one paper were extracted based on the article that was published most recently.

\section{Outcomes of interest and evidence synthesis}

Two study groups were defined and compared: (1) patients who underwent a primary suture repair of esophageal hiatus without mesh, and (2) patients who had hiatal repair with a mesh-augmentation technique. Five outcome parameters were synthesized and described for this metaanalysis:

(1) Recurrence of $\mathrm{HH}$, with subgroup analysis for different $\mathrm{HH}$ sizes.

(2) Total complications, and the incidence of dysphagia.

(3) Review of mortality and its cause.

(4) Visual analog scales (VAS) assessing postoperative symptoms, including heartburn, regurgitation, noncardiac chest pain and dysphagia.

(5) Meta-analysis of QOL measured by the Short-Form 36 (SF-36), Gastrointestinal Quality of Life Index (GQOLI) and GERD related Health Related Quality of Life (HRQL) questionnaire.

\section{Methods of analysis}

Data extracted from eligible trials were integrated using Review Manager 5.3 (The Nordic Cochrane Centre, Copenhagen, Denmark) provided by the Cochrane Collaboration. Additional statistical expertise was provided by an author-X Du. Outcomes reported in two or more studies were pooled for meta-analysis. Dichotomous and continuous outcomes were presented as odds ratio (OR) and mean differences (MD) respectively. Pooled OR with 95\% confidence intervals (CI) were calculated using the Mantel-Haenszel model to measure the effect of each type of repair on the risk for hernia recurrence and complications, and continuous variables were pooled using the inverse variance method to compare symptom scales and QOL. Heterogeneity was assessed using the $I^{2}$ statistic, a method expressing the percentage of variation across studies. $I^{2}$ values between 0 and $25 \%$ were considered to suggest a low level of variation, values above $25 \%$ a moderate level, and values above $75 \%$ a high level of heterogeneity. The fixed-effects model was used if heterogeneity was absent $\left(\chi^{2}\right.$ test, $P>0.1$, and $\left.I^{2}<50 \%\right)$, otherwise the random-effects model was used [13]. In addition, the random-effects model was applied to synthesize summative data to compensate for heterogeneity of non-randomized studies. Subgroup analysis was performed to assess the recurrence rate of $\mathrm{HH}$ and QOL.

\section{Results}

\section{Description of studies}

Figure 1 shows the PRISMA flow chart for the literature search. The initial database search retrieved 303 publications, and 11 eligible publications met the inclusion criteria, including four RCTs [14-17] three retrospective case-control [18-20] and four prospective case-control studies [21-24]. In two of the RCTs, different metrics from the same patients were described, and the data from these trials were included once in the meta-analysis. In the other two trials, different follow-up times were reported and both were included in the meta-analysis $[16,17,25,26]$. Basic characteristics of the included studies are summarized in Table 1, including case number, patient age, male-female ratio, follow-up time, and inclusion criteria. In total 1474 patients were included, 719 with mesh-augmentation and 755 with primary suture repair. Included studies were published between 2002 and 2016. Duration of follow-up ranged from 6 to 58 months. Not all studies provided data relevant to the outcomes of interest.

\section{Risk of bias within studies}

The study design (RCTs, prospective, or retrospective) and study characteristics are summarized in Table 1. Potential sources of bias, other than design, are summarized in Table 2. The main limitations resulted from poor description of the randomization processes $[14,15,22]$ as well as a lack of (or poor description of) the blinding processes [14, 15].

\section{Recurrence of $\mathbf{H H}$}

Clinical recurrence at short- to middle-term follow-up (6-36 months), defined as symptomatic recurrence, was evident in $2.6 \%$ of patients following mesh-augmented repair versus $9.4 \%$ following a suture repair (OR 0.23 , 95\% CI $0.14-0.39, P<0.00001)$, with no evidence of statistical heterogeneity $\left(\chi^{2}=3.93, P=0.950, I^{2}=0 \%\right)$. The Forest plot of odds ratios for the risk of hernia recurrence is presented in Fig. 2. Long-term (5 year) recurrence data were only available from one of the RCTs [25] and no significant differences were seen for mesh $(14 / 33,42.4 \%)$ versus suture repair (20/39, 51.3\%, OR 0.70, 95\% CI 0.28-1.78, $P=0.450)$.

To evaluate the impact of $\mathrm{HH}$ size on hernia recurrence rates, subgroup analyses were conducted. For these 
Fig. 1 Flow chart summarizing literature assessment

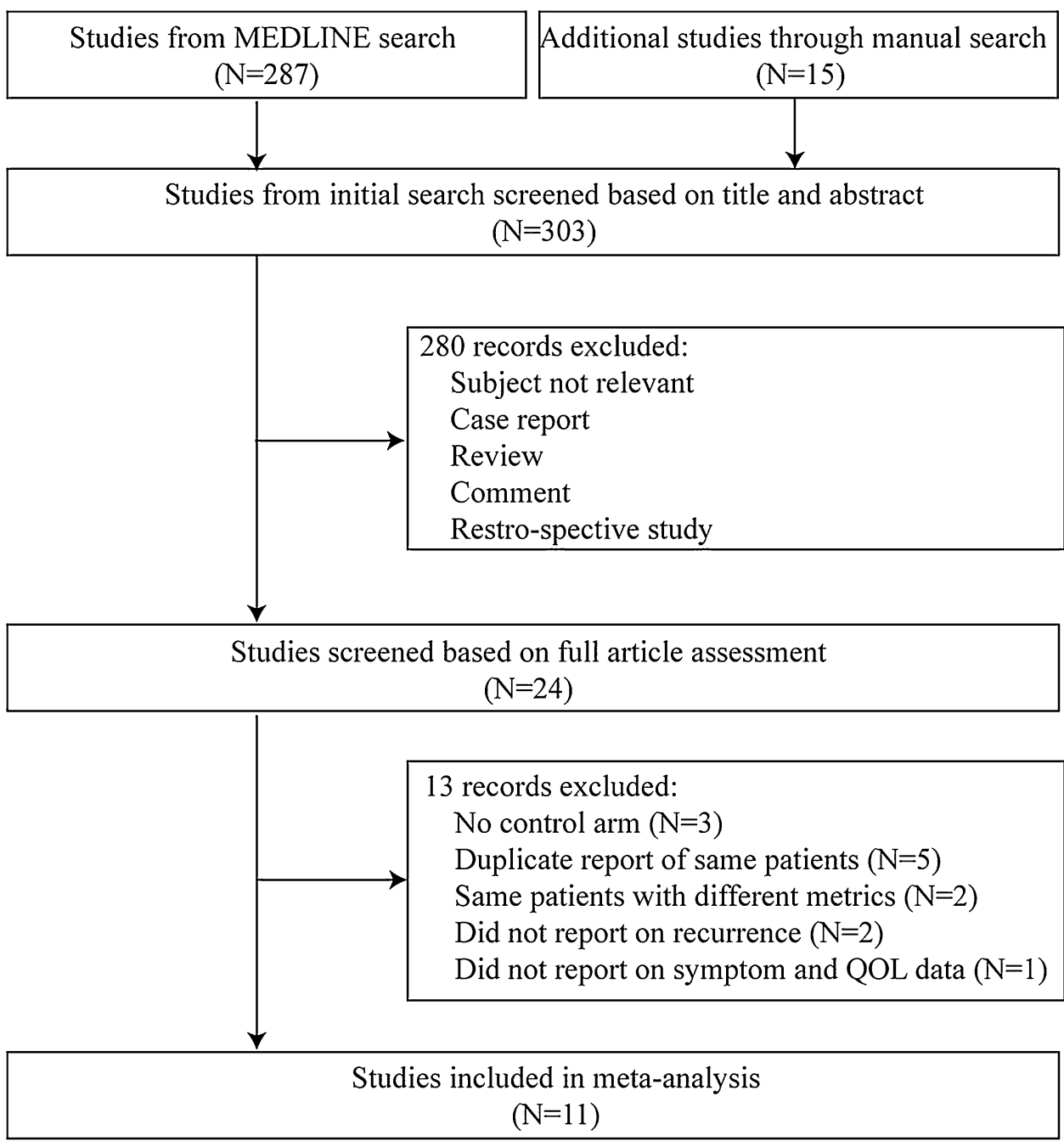

analyses, HHs were grouped into 3 size categories based on endoscopically measurements: very large (more than $8 \mathrm{~cm}$ ), large to very large (more than $5 \mathrm{~cm}$ ), and small (less than $5 \mathrm{~cm}$ ). Two studies with very large $\mathrm{HH}$, four studies with large to very large $\mathrm{HH}$ and two studies with small $\mathrm{HH}$ were included in subgroup meta-analysis. When totalgroup analyses were performed, the meta-analysis revealed a significant difference between the two arms for this parameter (OR 0.19, 95\% CI 0.10-0.38, $P<0.00001$, $I^{2}=0 \%$ ). In the subgroup with small, large to very large, and very large $\mathrm{HH}$, the results also favored mesh-augmented repair (Fig. 3) (Very large HH: OR 0.14, 95\% CI $0.03-0.57, P=0.006, I^{2}=31 \%$, Large to very large $\mathrm{HH}$ : OR $0.21,95 \%$ CI $0.09-0.51, P=0.0005, I^{2}=0 \%$, Small HH: OR $0.23,95 \%$ CI $0.05-1.01, P=0.050, I^{2}=38 \%$ ).

\section{Postoperative complications}

Complication rates of $4.9 \%$ were identified in both the mesh-augmented and primary suture repair groups (OR $0.81,95 \%$ CI $0.49-1.33, P=0.400$ ), with no evidence of significant statistical heterogeneity $\left(\chi^{2}=5.99, P=0.740\right.$, $I^{2}=0 \%$ ) in Fig. 4.

Postoperative dysphagia was analyzed separately to complications for the pooled analysis (Fig. 5). For the RCT reported by Watson et al., the dysphagia rate was calculated using the dysphagia for liquids analog score [17]. No significant differences for postoperative dysphagia were seen for the mesh-augmented group $(1.5 \%)$ versus primary suture repair $(1.7 \%)$, (OR $0.74,95 \%$ CI $0.31-1.76$, $P=0.500)$, with no evidence of statistical heterogeneity $\left(\chi^{2}=0.82, P=1.000, I^{2}=0 \%\right)$.

\section{Mortality}

Except for eight cases, no surgery-related death was associated with the two surgical techniques, and the two arms could not be validly compared for mortality. One patient died suddenly 7 days after surgery following a pulmonary embolism or myocardial infarct in Watson et al's study [17]. One died suddenly from myocardial infarction 14 days after surgery, and two died following massive 
Table 1 The basic characteristics of included randomized clinical trials

\begin{tabular}{|c|c|c|c|c|c|c|c|c|}
\hline Author & $\begin{array}{l}\text { Years of } \\
\text { publication }\end{array}$ & Study type & Country & $N($ mesh/suture $)$ & $\begin{array}{l}\text { Sex ratio } \\
\text { (male/ } \\
\text { female) }\end{array}$ & $\begin{array}{l}\text { Age (total or } \\
\text { mesh/suture) }\end{array}$ & $\begin{array}{l}\text { Detail of mesh } \\
\text { material }\end{array}$ & $\begin{array}{l}\text { Follow-up } \\
\text { (months) }\end{array}$ \\
\hline Asti [21] & 2016 & $\begin{array}{l}\text { Prospective } \\
\text { trial }\end{array}$ & Italy & $41 / 43$ & $20 / 64$ & $66 / 66$ & $\begin{array}{l}\text { Biological } \\
\text { mesh }\end{array}$ & 24 \\
\hline Crespin [18] & 2016 & $\begin{array}{l}\text { Retrospective } \\
\text { trial }\end{array}$ & $\begin{array}{l}\text { United } \\
\text { States }\end{array}$ & $110 / 36$ & $34 / 112$ & 61.5 & $\begin{array}{l}\text { Biological } \\
\text { mesh }\end{array}$ & 9 \\
\hline Frantzides [14] & 2002 & RCT & $\begin{array}{l}\text { United } \\
\text { States }\end{array}$ & $36 / 36$ & NA & $63 / 58$ & $\begin{array}{l}\text { Permanent } \\
\text { mesh }\end{array}$ & 30 \\
\hline Granderath [15] & 2005 & RCT & Germany & $50 / 50$ & $62 / 38$ & $48 / 49$ & $\begin{array}{l}\text { Permanent } \\
\text { mesh }\end{array}$ & 12 \\
\hline Kamolz [19] & 2002 & $\begin{array}{l}\text { Retrospective } \\
\text { trial }\end{array}$ & Austria & $100 / 100$ & $121 / 79$ & $48 / 50$ & $\begin{array}{l}\text { Permanent } \\
\text { mesh }\end{array}$ & 12 \\
\hline $\begin{array}{c}\text { Oeschager } \\
{[16,25]}\end{array}$ & 2006, 2011 & RCT & $\begin{array}{l}\text { United } \\
\text { States }\end{array}$ & $51 / 57$ & $27 / 81$ & $67 / 64$ & $\begin{array}{l}\text { Biological } \\
\text { mesh }\end{array}$ & $6 / 58$ \\
\hline Ozmen [22] & 2014 & $\begin{array}{l}\text { Prospective } \\
\text { trial }\end{array}$ & Turkey & $31 / 29$ & $34 / 26$ & $41 / 42$ & $\begin{array}{l}\text { Permanent } \\
\text { mesh }\end{array}$ & 12 \\
\hline Ringley [23] & 2006 & $\begin{array}{l}\text { Prospective } \\
\text { trial }\end{array}$ & $\begin{array}{l}\text { United } \\
\text { States }\end{array}$ & $22 / 22$ & $24 / 20$ & $58 / 52$ & $\begin{array}{l}\text { Biological } \\
\text { mesh }\end{array}$ & 6 \\
\hline Schmidt [20] & 2014 & $\begin{array}{l}\text { Retrospective } \\
\text { trial }\end{array}$ & $\begin{array}{l}\text { United } \\
\text { States }\end{array}$ & $38 / 32$ & $29 / 41$ & $51 / 41$ & $\begin{array}{l}\text { Biological } \\
\text { mesh }\end{array}$ & 12 \\
\hline Kepenekci [24] & 2007 & $\begin{array}{l}\text { Prospective } \\
\text { trial }\end{array}$ & Turkey & $176 / 335$ & $271 / 240$ & 48 & $\begin{array}{l}\text { Permanent } \\
\text { mesh }\end{array}$ & 24 \\
\hline $\begin{array}{l}\text { Watson [17] and } \\
\text { Koetje [26] }\end{array}$ & 2015 & RCT & Australia & $83 / 43$ & $40 / 86$ & $68 / 68$ & $\begin{array}{l}\text { Biological/ } \\
\text { Permanent } \\
\text { mesh }\end{array}$ & 12 \\
\hline
\end{tabular}

$R C T$ randomized controlled trials

Table 2 Risk of bias summary

\begin{tabular}{lccccccc}
\hline & (1) & (2) & (3) & (4) & (5) & (6) & (7) \\
\hline Asti 2016 & LR & UR & UR & LR & LR & UR & LR \\
Crespin 2016 & UR & UR & UR & LR & LR & LR & LR \\
Frantzides 2002 & UR & UR & UR & LR & LR & LR & LR \\
Granderath 2005 & UR & UR & UR & LR & LR & LR & LR \\
Kamolz 2002 & UR & UR & UR & LR & LR & LR & LR \\
Oeschager 2006, 2011 & LR & LR & LR & LR & LR & LR & UR \\
Ozmen 2014 & LR & UR & UR & LR & LR & LR & LR \\
Ringley 2006 & UR & UR & UR & LR & LR & LR & LR \\
Schmidt 2014 & UR & UR & UR & UR & LR & LR & LR \\
Kepenekci 2007 & UR & UR & UR & LR & LR & UR & LR \\
Watson and Koetje 2015 & LR & LR & LR & LR & LR & LR & LR \\
\hline (1):Random sequence & generation; & (2):Allocation & concealment; \\
(3):Blinding of participants and personnel (4):Blinding of outcomes \\
assessment; (5):Incomplete & outcome data; (6:Selective & reporting; \\
(7):Other bias. LR low risk, UR unclear risk, HR high risk & &
\end{tabular}

pulmonary embolism post-discharge in Oeschager's study [16]. Four died in Asti's study which is consisted of pneumothorax $(n=2)$, atrial fibrillation $(n=1)$, and acute urinary retention $(n=1)$, without mention of groups [21].

\section{Quality of life}

QOL assessment in the included studies general used either the SF-36, GIQLI, or HRQL questionnaires. Two studies used the SF-36 [16, 17], two used GIQLI [19, 22], and one used HRQL [21]. Only permanent mesh implantation studies were available for the GIQLI analysis, and biological mesh implantation studies for SF-36 and HRQL analysis. In this meta-analysis, SF-36 score was calculated by summing up all subscales according to the Oeschager et al's and Watson et al's studies. Subgroup analysis (Fig. 6) demonstrated significantly better SF-36 scores following biological mesh-augmentation compared to primary suture repair $(\mathrm{MD}=13.68,95 \%$ CI $2.51-24.85$, $P=0.020$ ), consistently, with a similar result in Asti et al's study $(\mathrm{MD}=1.30,95 \%$ CI $0.48-2.12, P=0.002)$. However, no significant differences in GIQLI scores were seen for permanent mesh versus suture repair $(\mathrm{MD}=0.78$, 95\% CI $-1.62-3.18, P=0.530)$. There was, however, significant statistical heterogeneity seen in the total QOL assessment $\left(\chi^{2}=62.35, P<0.00001, I^{2}=94 \%\right)$ and SF36 analysis $\left(\chi^{2}=11.53, P=0.0007, I^{2}=91 \%\right)$, but no evidence of significant statistical heterogeneity $\left(\chi^{2}=0.16\right.$, $P=0.69, I^{2}=0 \%$ ) for the GIQLI analysis. 


\begin{tabular}{|c|c|c|c|c|c|c|c|c|c|c|}
\hline Stucty or Subgroup & $\begin{array}{c}\text { Mesl } \\
\text { Events }\end{array}$ & Iotal & $\begin{array}{l}\text { Sutur } \\
\text { Events }\end{array}$ & e & Weight & $\begin{array}{c}\text { Odds Ratio } \\
\text { M-H, Fixed, } 95 \% \mathrm{Cl}\end{array}$ & & $\begin{array}{r}\text { Odds } \\
\text { M-H, Fixe }\end{array}$ & $\begin{array}{l}\text { Ratio } \\
\text { ed, } 95 \% \mathrm{Cl}\end{array}$ & \\
\hline Asti 2016 & 0 & 41 & 3 & 43 & $4.8 \%$ & $0.14[0.01,2.79]$ & 4 & & & \\
\hline Crespin 2016 & 6 & 110 & 6 & 36 & $12.1 \%$ & $0.29[0.09,0.96]$ & & & & \\
\hline Frantzides 2002 & 0 & 36 & 8 & 36 & $11.9 \%$ & $0.05[0.00,0.83]$ & & & & \\
\hline Granderath 2006 & 4 & 50 & 13 & 50 & $16.9 \%$ & $0.25[0.07,0.82]$ & & & & \\
\hline Kamolz 2002 & 0 & 100 & 5 & 100 & $7.7 \%$ & $0.09[0.00,1.58]$ & $\leftarrow$ & & & \\
\hline Oelschlager 2011 & 4 & 45 & 12 & 49 & $14.8 \%$ & $0.30[0.09,1.01]$ & & & & \\
\hline Ozmen 2014 & 0 & 30 & 1 & 31 & $2.1 \%$ & $0.33[0.01,8.51]$ & & & & \\
\hline Ringley 2006 & 0 & 22 & 2 & 22 & $3.5 \%$ & $0.18[0.01,4.02]$ & & & & \\
\hline Schmidt 2014 & 0 & 38 & 5 & 32 & $8.3 \%$ & $0.06[0.00,1.22]$ & & & & \\
\hline Turkcapar 2007 & 3 & 164 & 13 & 313 & $12.4 \%$ & $0.43[0.12,1.53]$ & & & & \\
\hline Watson 2015 & 2 & 83 & 3 & 43 & $5.5 \%$ & $0.33[0.05,2.05]$ & & & & \\
\hline Total $(95 \% \mathrm{Cl})$ & & 719 & & 755 & $100.0 \%$ & $0.23[0.14,0.39]$ & & & & \\
\hline Total events & 19 & & 31 & & & & & & & \\
\hline $\begin{array}{l}\text { Heterogeneity: } \mathrm{Chi}^{2} \\
\text { Test for overall effec }\end{array}$ & $\begin{array}{l}93, d f= \\
=5.57\end{array}$ & $\begin{array}{l}10<P= \\
P<0.00\end{array}$ & $\begin{array}{l}=0.95) ; 1^{2} \\
0001)\end{array}$ & $=0 \%$ & & & 0.01 & $\begin{array}{c}0.1 \\
\text { Favours (Mesh) }\end{array}$ & 1 Favours ( & $\begin{array}{cc}10 & 100 \\
\text { (Suture) } & \end{array}$ \\
\hline
\end{tabular}

Fig. 2 Forrest plot of the odds ratio for early recurrence

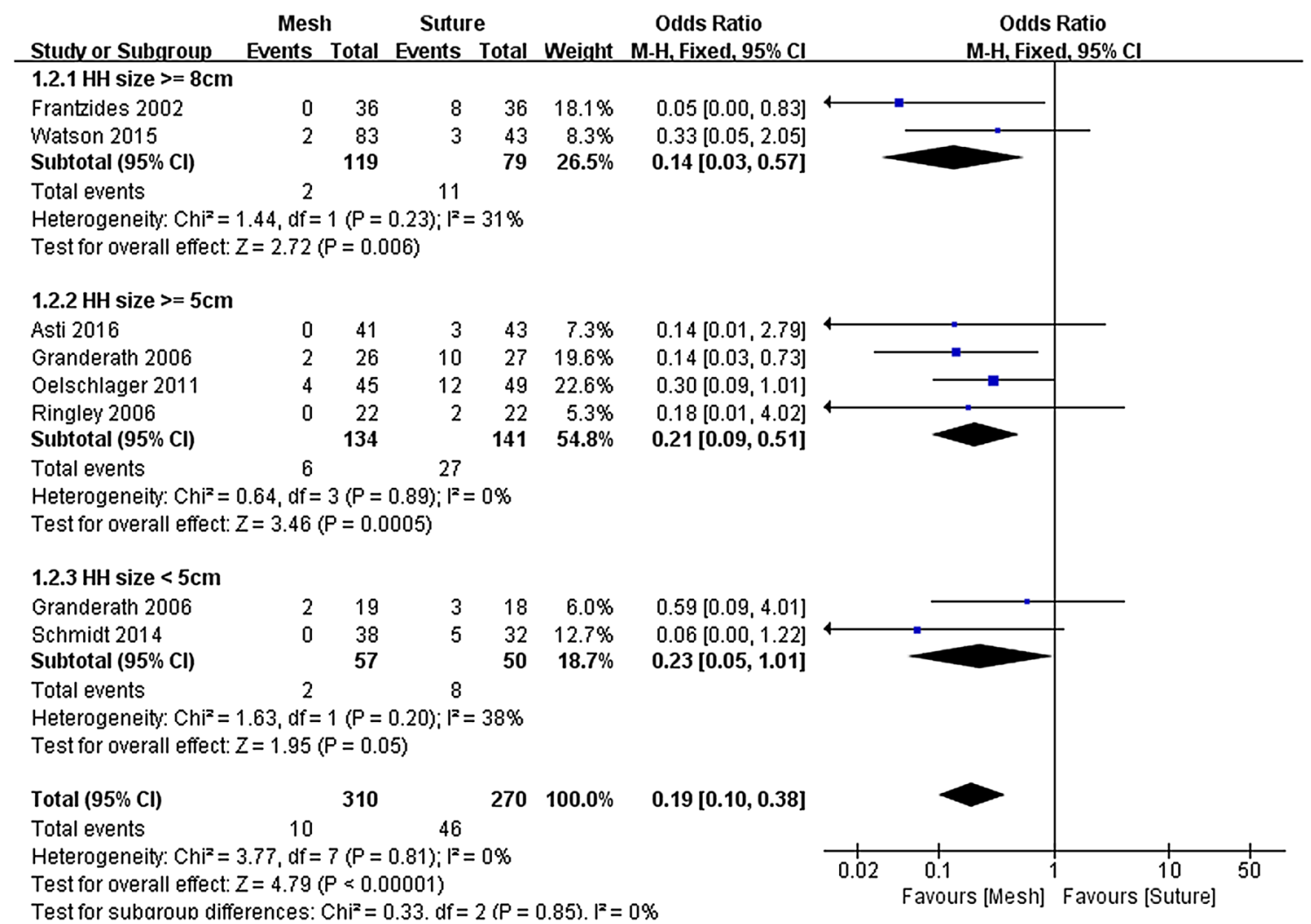

Fig. 3 Forrest plot of the subgroup odds ratio for early recurrence by $\mathrm{HH}$ size

\section{Improvement of symptoms (analog symptom scores)}

Four studies [16, 17, 20, 23] used analog scales to report various symptoms before and after surgery, including heartburn, regurgitation, non-cardiac chest pain, and dysphagia. Improvements in the analog symptom scores were calculated and included in a meta-analysis of each symptom (Fig. 7). Meta-analysis revealed no significant difference for heartburn, regurgitation, and noncardiac chest pain between the two groups. The extent of improvement in dysphagia was greater following repair by sutures alone $(\mathrm{MD}=1.47,95 \%$ CI $0.20-2.74, P=0.020)$. However, excessive heterogeneities were seen for the analysis of all analog symptom scores $\left(I^{2}>75 \%\right)$.

\section{Discussion}

Laparoscopic fundoplication for GERD commenced in 1991 [27], and has become the "gold standard" surgical approach in patients with medical-refractory GERD [28]. A 


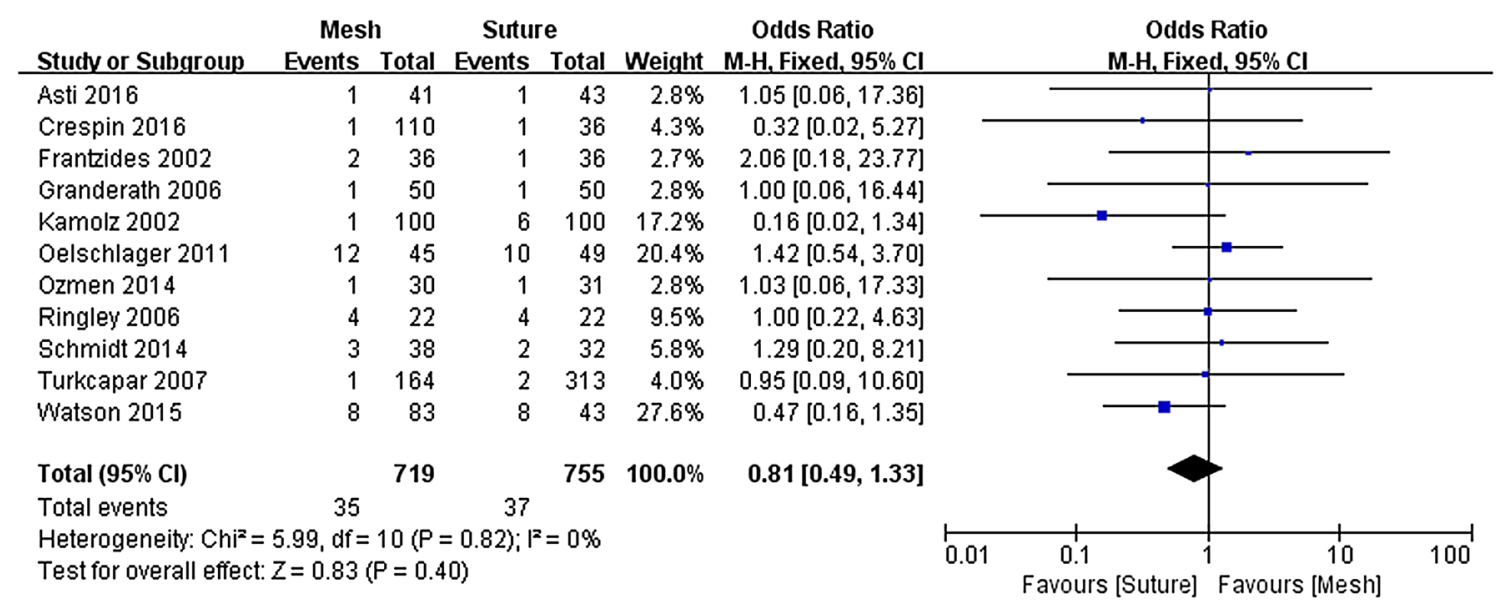

Fig. 4 Forrest plot of the odds ratio for postoperative complications

\begin{tabular}{|c|c|c|c|c|c|c|c|c|c|c|c|}
\hline Study or Subgroup & $\begin{array}{c}\text { Mest } \\
\text { Events }\end{array}$ & Total & $\begin{array}{c}\text { Sutur } \\
\text { Events }\end{array}$ & Total & Weight & $\begin{array}{c}\text { Odds Ratio } \\
\text { M-H, Fixed, 95\% Cl }\end{array}$ & & $\begin{array}{r}\text { Odds } \\
\text { M-H, Fixe }\end{array}$ & $\begin{array}{l}\text { Ratio } \\
\text { d, } 95 \% \mathrm{Cl}\end{array}$ & & \\
\hline Asti 2016 & 1 & 41 & 1 & 43 & $8.0 \%$ & $1.05[0.06,17.36]$ & & & & & \\
\hline Crespin 2016 & 1 & 110 & 1 & 36 & $12.5 \%$ & $0.32[0.02,5.27]$ & & & & & \\
\hline Frantzides 2002 & 0 & 36 & 0 & 36 & & Not estimable & & & & & \\
\hline Granderath 2006 & 1 & 50 & 1 & 50 & $8.2 \%$ & $1.00[0.06,16.44]$ & & & & & \\
\hline Kamolz 2002 & 1 & 100 & 2 & 100 & $16.5 \%$ & $0.49[0.04,5.55]$ & & & & & \\
\hline Ormen 2014 & 1 & 30 & 2 & 31 & $15.9 \%$ & $0.50[0.04,5.82]$ & & & & & \\
\hline Ringley 2006 & 1 & 22 & 1 & 22 & $8.0 \%$ & $1.00[0.06,17.07]$ & & & & & \\
\hline Schmidt 2014 & 1 & 38 & 1 & 32 & $8.8 \%$ & $0.84[0.05,13.95]$ & & & & & \\
\hline Turkcapar $200 ?$ & 1 & 164 & 2 & 313 & $11.4 \%$ & $0.95[0.09,10.60]$ & & & & & \\
\hline Watson 2015 & 2 & 83 & 1 & 43 & $10.7 \%$ & $1.04[0.09,11.77]$ & & & & & \\
\hline Total $(95 \% \mathrm{Cl})$ & & 674 & & 706 & $100.0 \%$ & $0.74[0.31,1.76]$ & & & & & \\
\hline Total events & 10 & & 12 & & & & & & & & \\
\hline $\begin{array}{l}\text { Heterogeneity: } \mathrm{Chi}^{2}= \\
\text { Test for overall effec }\end{array}$ & $\begin{array}{l}0.82, d f= \\
Z=0.68(\end{array}$ & $\begin{array}{l}8(P= \\
P=0.5\end{array}$ & $\begin{array}{l}1.00) ;\left.\right|^{2}= \\
0)\end{array}$ & & & & 01 & $\begin{array}{c}0.1 \\
\text { Favours [Suture] }\end{array}$ & 1 Favours & $\begin{array}{c}10 \\
\text { [Mesh] }\end{array}$ & 100 \\
\hline
\end{tabular}

Fig. 5 Forrest plot of the odds ratio for postoperative dysphagia

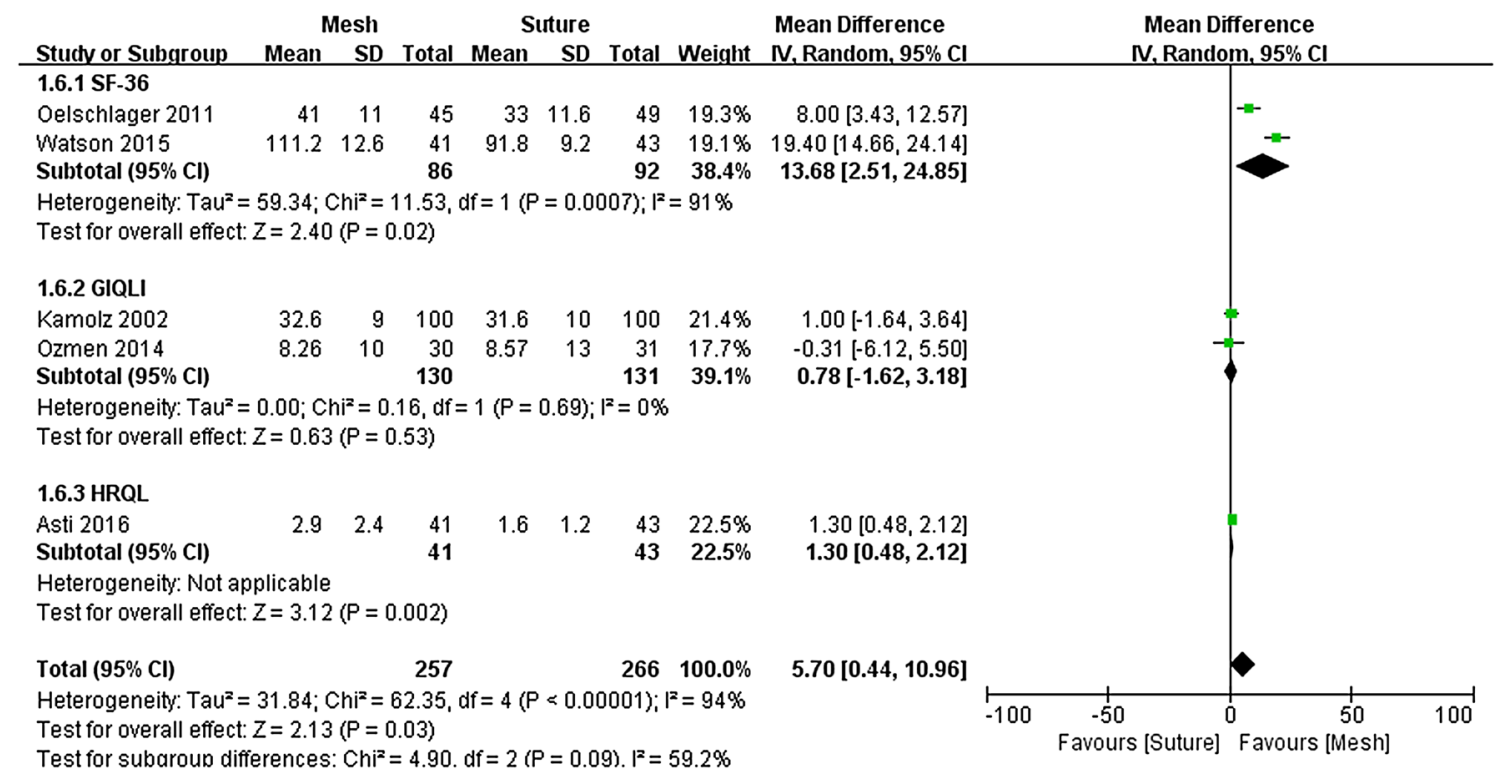

Fig. 6 Forrest plot of the mean difference for quality of life 


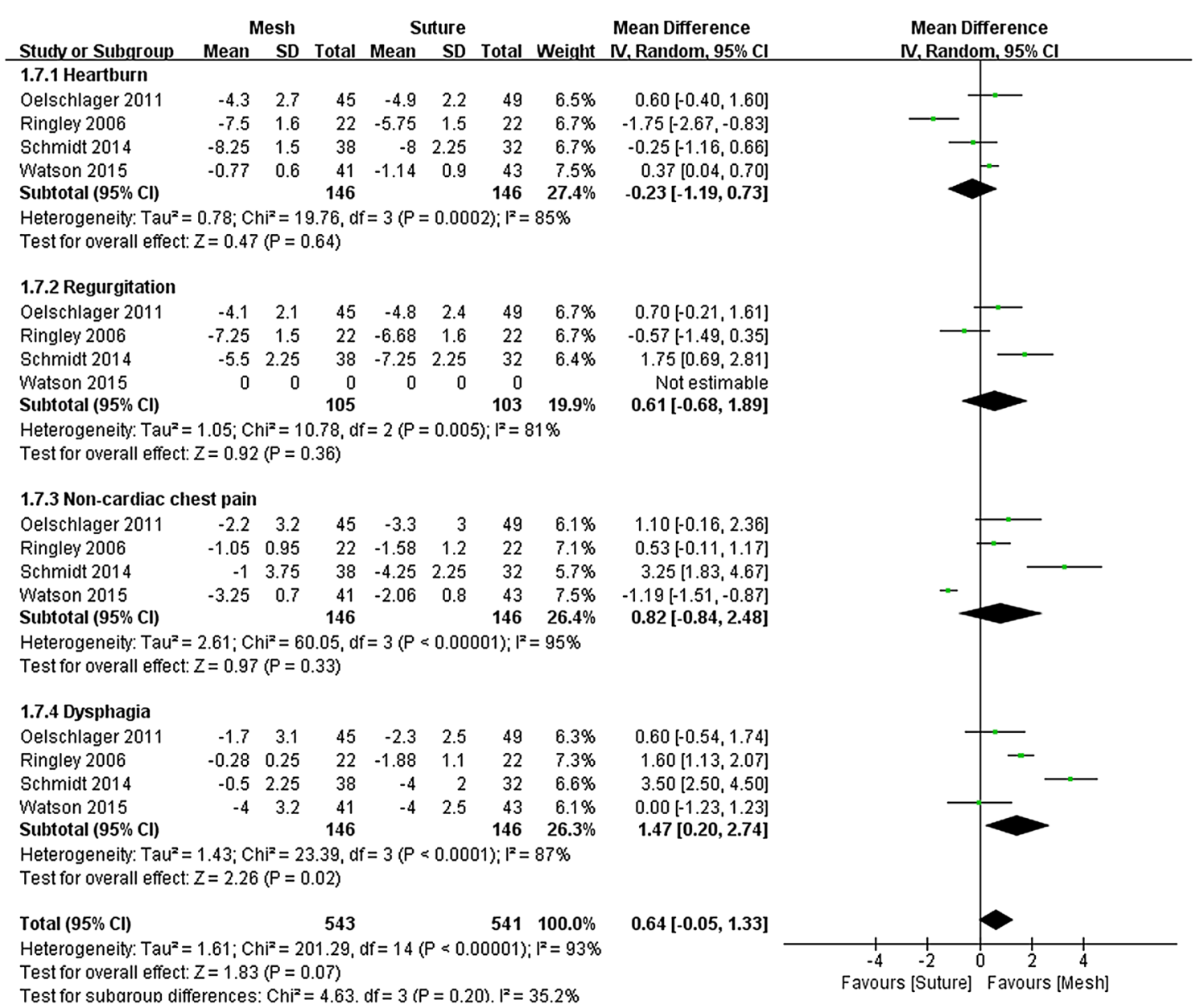

Fig. 7 Forrest plot of the mean difference for analog symptoms scores

proportion of patients also present with a very large $\mathrm{HH}$, and this scenario is frequently encountered. HH repair using sutures was initially used for laparoscopic repair. Subsequent studies reported high rates of radiological recurrence of hernias, and this provided impetus to the use of mesh for hiatal repair during repair of large $\mathrm{HH}$, even though most of the identified postoperative hernias were small and asymptomatic. Currently, the use of mesh remains controversial, with little agreement about whether or not to use mesh, what type of mesh (permanent vs. absorbable), mesh configuration, and concern about the risk of mesh-related complications.

Current studies comparing mesh versus suture repair are limited to four RCTs, and a small number of non-randomized case-control studies. Our meta-analysis suggests that the use of mesh is associated with a reduced rate of hernia recurrence compared to primary suture repair at short-term follow-up of 6-12 months. However, longer term data are only available from one RCT [25]. Oelschlager et al. initially reported a significant reduction in hernia rates at short-term follow-up following repair with
Surgisis mesh, but no difference at longer term follow-up at 5 years, with recurrence rates of $>50 \%$ in both groups. The conclusions that can be drawn from Oelschlager et al's later follow-up report are limited by possible attrition bias, with only $66.7 \%$ of patients contributing to late follow-up. Frantzides et al's RCT [14] showed that PTFE mesh decreased hernia recurrence rates from 22 to $0 \%$ for very large $\mathrm{HH}(d \geq 8 \mathrm{~cm})$ at $2^{1 / 2}$ years follow-up. While these data suggest that PTFE mesh might reduce hernia recurrence, many surgeons consider PTFE mesh to be associated with an excessive risk of mesh erosion and dysphagia, and have not adopted this approach. Furthermore, later followup from this study has not been reported.

Despite the potential for mesh to decrease hernia recurrence rates, arguments continue about the risk and impact of mesh-associated complications [4]. In this metaanalysis, mesh-augmentation did not appear to be associated with an increased risk of complications. However, our analysis only evaluated the overall complication rate, not specific complications, and as follow-up was generally short, late complications such as mesh erosion could not be 
considered. Mesh-augmentation might lead to increased perihiatal scarring, and thereby contribute to dysphagia. However, at one-year follow-up, the prevalence of postoperative dysphagia was not significantly increased following mesh-augmentation. Even though the impact of different mesh types and mesh configurations was difficult to determine due to the heterogeneity of surgical techniques in the studies reviewed, it is possible that dysphagia is not impacted by mesh repair.

Apart from the integrity of the hernia repair, QOL after surgery is also an important consideration, and global measures of outcome that integrate improvements in symptoms and post-surgical side effects should also be considered when determining surgical success [29]. It is well known that laparoscopic fundoplication for GERD can significantly improve QOL [30, 31]. To compare QOL improvements across the different trial cohorts, we limited the meta-analysis to the SF-36, GIQOL, and HRQL scales. Our results suggested that mesh repair was associated with greater short-term improvements in the SF-36 scales, and the magnitude of the OR was slightly in favor of the mesh group when using HRQL, although differences were not seen for the GIQOL score. The data underpinning the SF36 and HRQL scores were from studies that used biological mesh, whereas the GIQOL data came from studies that used a permanent mesh. It is feasible that the different types of mesh impact QOL differently, and that the use of a biological mesh reduces or eliminates the risk of problems which might accompany excessive scarring around a permanent mesh material. However, the data in our study are not definitive, and this is an area for future research. Moreover, our analysis suggests that mesh-augmentation does not impact many of the symptoms assessed by analog scales, including typical symptoms of GERD (heartburn and regurgitation) and atypical symptoms like non-cardiac chest pain. However, dysphagia appeared to be impacted by mesh-augmentation, with lower levels of post-surgery improvement, compared to a primary suture repair, although these results should be considered cautiously as the heterogeneity was high $\left(I^{2}=87 \%\right)$.

Our meta-analysis has some inherent limitations. Seven of the eleven studies included in the meta-analysis were not randomized. This increases the risk of selection and detection bias. A wide variety of surgical techniques were also used, mesh shapes and mesh types were used (biological and permanent mesh), and differences between techniques were beyond the scope of this meta-analysis. In addition, outcomes for most studies were short term, with only one study reporting longer term outcomes, and these outcomes differed significantly from the earlier reported short-term outcomes.

In conclusion, our meta-analysis suggests that meshaugmentation should at least be considered for repair of
HH. Compared to primary suture repair, mesh repair of $\mathrm{HH}$ appears to be associated with a lower recurrence risk at short-term follow-up, a similar pattern of complications and reflux symptoms, but perhaps offset by more dysphagia. Biological mesh was also associated with better short-term QOL scores. However, the limitations of shortterm follow-up in most studies and heterogeneity of surgical techniques, suggest that data should be interpreted cautiously, and the case for routine use of mesh for $\mathrm{HH}$ repair is yet to be proven. Further studies should also consider the impact of different mesh configurations and types.

Acknowledgements This work was supported by Beijing 215 Hygiene Talents funding of China (008-0088 to D Liu), and a Clinical Research Grant from Xuanwu Hospital, China (2016-04 to C Zhang).

Author contributions CZ, DL, FL, DIW designed the study; CZ, DL, DIW, and JHK coordinated the study; CZ, DL, FL, DIW, XG, $\mathrm{XD}, \mathrm{CY}$, TL, and ZW performed the study; CZ, DL, CY, XD, and TL analyzed the data; FL and ZW helped to draft the manuscript; $\mathrm{CZ}$ wrote the manuscript; and DIW revised the manuscript. All authors read and approved the final manuscript.

\section{Compliance wih ethical standards}

Disclosures Drs. Chao Zhang, Diangang Liu, Fei Li, David I. Watson, Xiang Gao, Jan H. Koetje, Tao Luo, Chao Yan, Xing Du, Zhonggao Wang have no conflict of interest, or financial ties to disclose.

Open Access This article is distributed under the terms of the Creative Commons Attribution 4.0 International License (http://crea tivecommons.org/licenses/by/4.0/), which permits unrestricted use, distribution, and reproduction in any medium, provided you give appropriate credit to the original author(s) and the source, provide a link to the Creative Commons license, and indicate if changes were made.

\section{References}

1. Guidelines for surgical treatment of gastroesophageal reflux disease (GERD) (1998) Society of American Gastrointestinal Endoscopic Surgeons (SAGES). Surg Endosc 12(2):186-188

2. Frantzides CT, Carlson MA, Loizides S, Papafili A, Luu M, Roberts J, Zeni T, Frantzides A (2010) Hiatal hernia repair with mesh: a survey of SAGES members. Surg Endosc 24(5): 1017-1024. doi:10.1007/s00464-009-0718-6

3. Pfluke JM, Parker M, Bowers SP, Asbun HJ, Smith CD (2012) Use of mesh for hiatal hernia repair: a survey of SAGES members. Surg Endosc 26(7):1843-1848. doi:10.1007/s00464-0122150-6

4. Herbella FA, Patti MG, Del Grande JC (2011) Hiatal mesh repair-current status. Surg Laparosc Endosc Percutan Tech 21(2):61-66. doi:10.1097/SLE.0b013e31820e6e2a00129689-201 104000-00001

5. Stadlhuber RJ, Sherif AE, Mittal SK, Fitzgibbons RJ Jr, Michael Brunt L, Hunter JG, Demeester TR, Swanstrom LL, Smith CD, Filipi CJ (2009) Mesh complications after prosthetic reinforcement of hiatal closure: a 28-case series. Surg Endosc 23(6):1219-1226. doi:10.1007/s00464-008-0205-5 
6. Parsak CK, Erel S, Seydaoglu G, Akcam T, Sakman G (2011) Laparoscopic antireflux surgery with polyglactin (vicryl) mesh. Surg Laparosc Endosc Percutan Tech 21(6):443-449. doi:10. 1097/SLE.0b013e31823acc8700129689-201112000-00012

7. Granderath FA, Carlson MA, Champion JK, Szold A, Basso N, Pointner R, Frantzides CT (2006) Prosthetic closure of the esophageal hiatus in large hiatal hernia repair and laparoscopic antireflux surgery. Surg Endosc 20(3):367-379. doi:10.1007/ s00464-005-0467-0

8. Koch OO, Asche KU, Berger J, Weber E, Granderath FA, Pointner R (2011) Influence of the size of the hiatus on the rate of reherniation after laparoscopic fundoplication and refundopilication with mesh hiatoplasty. Surg Endosc 25(4):1024-1030. doi:10.1007/s00464-010-1308-3

9. Huddy JR, Markar SR, Ni MZ, Morino M, Targarona EM, Zaninotto G, Hanna GB (2016) Laparoscopic repair of hiatus hernia: does mesh type influence outcome? A meta-analysis and European survey study. Surg Endosc 30(12):5209-5221. doi:10. 1007/s00464-016-4900-3

10. Muller-Stich BP, Achtstatter V, Diener MK, Gondan M, Warschkow R, Marra F, Zerz A, Gutt CN, Buchler MW, Linke GR (2015) Repair of paraesophageal hiatal hernias-is a fundoplication needed? A randomized controlled pilot trial. J Am Coll Surg 221(2):602-610. doi:10.1016/j.jamcollsurg.2015.03.003S10 72-7515(15)00191-X

11. Muller-Stich BP, Kenngott HG, Gondan M, Stock C, Linke GR, Fritz F, Nickel F, Diener MK, Gutt CN, Wente M, Buchler MW, Fischer L (2015) Use of mesh in laparoscopic paraesophageal hernia repair: a meta-analysis and risk-benefit analysis. PLoS One 10(10):e0139547. doi:10.1371/journal.pone.0139547

12. Moher D, Liberati A, Tetzlaff J, Altman DG (2009) Preferred reporting items for systematic reviews and meta-analyses: the PRISMA statement. J Clin Epidemiol 62(10):1006-1012. doi:10. 1016/j.jclinepi.2009.06.005S0895-4356(09)00179-6

13. DerSimonian R, Laird N (1986) Meta-analysis in clinical trials. Control Clin Trials 7(3):177-188.

14. Frantzides CT, Madan AK, Carlson MA, Stavropoulos GP (2002) A prospective, randomized trial of laparoscopic polytetrafluoroethylene (PTFE) patch repair vs simple cruroplasty for large hiatal hernia. Arch Surg 137(6):649-652

15. Granderath FA, Schweiger UM, Kamolz T, Asche KU, Pointner R (2005) Laparoscopic Nissen fundoplication with prosthetic hiatal closure reduces postoperative intrathoracic wrap herniation: preliminary results of a prospective randomized functional and clinical study. Arch Surg 140(1):40-48. doi:10.1001/arch surg. 140.1 .40

16. Oelschlager BK, Pellegrini CA, Hunter J, Soper N, Brunt M, Sheppard B, Jobe B, Polissar N, Mitsumori L, Nelson J, Swanstrom L (2006) Biologic prosthesis reduces recurrence after laparoscopic paraesophageal hernia repair: a multicenter, prospective, randomized trial. Ann Surg 244(4):481-490. doi:10. 1097/01.sla.0000237759.42831.03

17. Watson DI, Thompson SK, Devitt PG, Smith L, Woods SD, Aly A, Gan S, Game PA, Jamieson GG (2015) Laparoscopic repair of very large hiatus hernia with sutures versus absorbable mesh versus nonabsorbable mesh: a randomized controlled trial. Ann Surg 261(2):282-289. doi:10.1097/sla.0000000000000842

18. Crespin OM, Yates RB, Martin AV, Pellegrini CA, Oelschlager BK (2016) The use of crural relaxing incisions with biologic mesh reinforcement during laparoscopic repair of complex hiatal hernias. Surg Endosc 30(6):2179-2185. doi:10.1007/s00464-015-4522-1

19. Kamolz T, Granderath FA, Bammer T, Pasiut M, Pointner R (2002) Dysphagia and quality of life after laparoscopic Nissen fundoplication in patients with and without prosthetic reinforcement of the hiatal crura. Surg Endosc 16(4):572-577. doi:10. 1007/s00464-001-9136-0

20. Schmidt E, Shaligram A, Reynoso JF, Kothari V, Oleynikov D (2014) Hiatal hernia repair with biologic mesh reinforcement reduces recurrence rate in small hiatal hernias. Dis Esophagus 27(1):13-17. doi:10.1111/dote.12042

21. Asti E, Lovece A, Bonavina L, Milito P, Sironi A, Bonitta G, Siboni S (2016) Laparoscopic management of large hiatus hernia: five-year cohort study and comparison of mesh-augmented versus standard crura repair. Surg Endosc 30(12):5404-5409. doi:10. 1007/s00464-016-4897-710.1007/s00464-016-4897-7

22. Ozmen MM, Bilgic IC, Kilinc U, Gelecek S, Moran M (2014) Prospective evaluation of crural repair with and without doublesided mesh reinforcement. Surg Laparosc Endosc Percutan Tech 24(4):353-356. doi:10.1097/sle.0000000000000045

23. Ringley CD, Bochkarev V, Ahmed SI, Vitamvas ML, Oleynikov D (2006) Laparoscopic hiatal hernia repair with human acellular dermal matrix patch: our initial experience. Am J Surg 192(6):767-772. doi:10.1016/j.amjsurg.2006.08.042

24. Kepenekci I (2007) Laparoscopic fundoplication with prosthetic hiatal closure. World J Surg 31(11):2169-2176. doi:10.1007/ s00268-007-9066-7

25. Oelschlager BK, Pellegrini CA, Hunter JG, Brunt ML, Soper NJ, Sheppard BC, Polissar NL, Neradilek MB, Mitsumori LM, Rohrmann CA, Swanstrom LL (2011) Biologic prosthesis to prevent recurrence after laparoscopic paraesophageal hernia repair: long-term follow-up from a multicenter, prospective, randomized trial. J Am Coll Surg 213(4):461-468. doi:10.1016/j. jamcollsurg.2011.05.017

26. Koetje JH, Irvine T, Thompson SK, Devitt PG, Woods SD, Aly A, Jamieson GG, Watson DI (2015) Quality of life following repair of large hiatal hernia is improved but not influenced by use of mesh: results from a randomized controlled trial. World J Surg 39(6):1465-1473. doi:10.1007/s00268-015-2970-3

27. Geagea T (1991) Laparoscopic Nissen's fundoplication: preliminary report on ten cases. Surg Endosc 5(4):170-173

28. Niebisch S, Peters JH (2012) Update on fundoplication for the treatment of GERD. Curr Gastroenterol Rep 14(3):189-196. doi:10.1007/s11894-012-0256-6

29. Zhang C, Wu J, Hu Z, Yan C, Gao X, Liang W, Liu D, Li F, Wang Z (2016) Diagnosis and anti-reflux therapy for GERD with respiratory symptoms: a study using multichannel intraluminal impedance-pH monitoring. PLoS One 11(8):e0160139. doi:10. 1371/journal.pone.0160139PONE-D-16-00122

30. Kamolz T, Bammer T, Wykypiel H Jr, Pasiut M, Pointner R (2000) Quality of life and surgical outcome after laparoscopic Nissen and Toupet fundoplication: one-year follow-up. Endoscopy 32(5):363-368. doi:10.1055/s-2000-9000

31. Lundell L, Miettinen P, Myrvold HE, Pedersen SA, Liedman B, Hatlebakk JG, Julkonen R, Levander K, Carlsson J, Lamm M, Wiklund I (2001) Continued (5-year) followup of a randomized clinical study comparing antireflux surgery and omeprazole in gastroesophageal reflux disease. J Am Coll Surg 192(2):172-179 discussion 179-181 